\title{
印尼峇淡慈容学校初中部教师汉字教学方法和学生汉字学习方法调查研究
}

\section{ANALISIS METODE PENGAJARAN AKSARA MANDARIN GURU \\ DAN METODE PEMBELAJARAN AKSARA MANDARIN SISWA \\ SMP MAITREYAWIRA BATAM, INDONESIA}

\author{
Meta Eka Putri ${ }^{1}$; Herman ${ }^{2}$ \\ Pendidikan Bahasa Mandarin, Universitas Universal \\ Metaeka123@gmail.com; hermanuvers72@gmail.com
}

\section{摘要}

印中的友好关系，印中的经济贸易合作，印尼政府对汉语教育的支持影响到印尼汉语 教育的发展, 使大家意识到学习汉语的重要性。在学习汉语的过程当中, 汉字成为汉语教 学中的重点之一。为了解印尼峇淡慈容学校初中部汉字教学状况, 本文通过文献研究法、 实地考察法、问卷调查法、访谈调查法和描述法对印尼峇淡慈容初中部汉字教学进行研究。 调查中发现, 慈容初中的汉语教师使用了丰富的教学方法, 有展示汉字法、讲解汉字法、 游戏法、听写法和抄写法。虽然如此, 还有不少学生在汉字书写方面依然出现书写偏误, 包括笔画偏误、笔顺偏误和结构偏误等。为提升学生的学习能力和提高教师的教学能力, 本文提出了几个建议, 教师使用趣味性的教学方法, 学生提高记忆力的汉字学习方式。

[关键词］慈容学校; 汉字教学; 书写偏误; 建议

\begin{abstract}
Abstrak
Hubungan persahabatan antara Indonesia dan Tiongkok, kerjasama ekonomi dan perdagangan Indonesia dengan Tiongkok, dan dukungan pemerintah Indonesia terhadap pembelajaran bahasa Mandarin mempengaruhi pesatnya perkembangan pendidikan bahasa Mandarin Indonesia, sehingga tidak sedikit pelajar merasakan pentingnya menguasai bahasa Mandarin. Dalam proses pembelajaran bahasa Mandarin, aksara Mandarin merupakan salah satu materi penting dalam pembelajarannya. Untuk memahami kondisi pembelajaran aksara bahasa Mandarin siswa, penelitian ini mengambil objek penelitian siswa SMP Maitreyawira Batam, dengan metode penelitian deskriptif kualitatif, data diambil dengan metode survei, wawancara, observasi dan survei literatur, dengan judul "Analisis Metode Pengajaran Aksara Mandarin Guru
\end{abstract}


dan Metode Pembelajaran Aksara Mandarin Siswa SMP Maitreyawira Batam, Indonesia”. Proses penelitian menemukan, bahwa guru telah menggunakan metode pengajaran yang beragam seperti metode ceramah, metode permainan, metode menulis dll. Walau demikian pada kenyataannya masih banyak siswa belum dapat menulis aksara bahasa Mandarin dengan baik dan benar, serta masih sering terjadi kesalahan penulisan seperti: bihua yang salah, urutan penulisan yang tidak tepat, struktur huruf yang tidak rapi, dll. Untuk menyelesaikan masalah ini, penelitian ini memberikan beberapa saran untuk mengatasi masalah ini, seperti: guru mengunakan metode pembelajaran menyenangkan, siswa menggunakan metode pembelajaran daya ingat.

Kata Kunci : SMP Maitreyawira Batam, Pembelajaran Aksara Mandarin, Kesalahan Penulisan, Saran

\section{一、引言}

\section{1. 研究背景}

随着汉语走向国际化, 印中的友好关系, 印中经济的不断发展, 印尼政府对汉语教育的 支持，使印尼汉语教育不断发展，印尼“汉语热”不断升温，印尼人学习汉语的热情空前高涨。 随着印尼华文教育的日益发展, 在印尼越来越多的学校开设汉语课程, 尤其是在以华裔学 生为主的私立学校。目前, 印尼华人聚集的地区已经形成了从幼儿园、小学、中学到大学 比较完整的华文教育发展体系。其中之一就是印尼廖海群岛省峇淡岛。在峇淡岛, 很多学 校已经把汉语课定位为必修课, 慈容学校在内。

慈容初中是峇淡岛的一所私立学校之一, 已有14年的历史。目前慈容初中学校的学生总 共有786左右, 有5位汉语老师。为了提高汉语教学质量, 慈容初中设不同汉语能力的班, 实行了 “分班制”, 即根据学生的汉语能力, 分配至不同的班级-一初级班、中级班和高级 班。通过分班考试便能了解学生的汉语水平，根据考试成绩进行分班。实行分班制度的目 的在于提高学生的汉语能力。虽然慈容初中很重视汉语, 但是学校开设的汉语课课型单一, 在课程设置上没有单独开设“听、说、读、写”的课程, 所有的汉语学习任务都是在一门综合 课内实现。

汉语教学中, 听、说、读、写是缺一不可的四个方面内容, 要让学生学好汉语, 特别是 汉语的读写能力, 学生必须能掌握汉字。而我们的汉语教学对于作为书面语基础的汉字却 没有给予应有的重视。 
对于汉字教学有不少研究者研究, 如吕必松, 他于1993年在《汉字教学与汉语教学》中 指出汉字教学是对外汉语教学的重要组成部分, 汉字教学和汉语教学是相互影响和促进的, 要提高对外汉语教学的质量就必须加强和深入汉字研究。从吕必松的观点来分析, 我们可 以意识到汉字教学的重要性也对汉字教学方法的研究有深远的意义, 因为教师扮演着非常 重要的角色, 通过正确有效的汉字教学的方法, 不仅能提高学生的汉字能力, 还能促进学 习者对汉字学习的兴趣。所以, 汉字教学方法对于学生学习汉字的效果有着密切关系。

万业馨的《文字学视野中的部件教学》（2001年）中将文字学与对外汉语汉字教学紧密 结合起来, 对对外汉字部件教学进行了深入研究, 认为不能笼统地说汉字教学应由部件到 整字, 对于与形声字不同音或者常用程度不如形声字的声旁字, 则应采用由整字到部件的 教学方法。

余国江的《传统识字教学的优点及其对对外汉字教学的启示》（2007年）中认为传统识 字教学在三个方面对对外汉字教学有稗益：树立 “字本位” 观念, 重视 “字” 的教学; 精 选高频用字, 采取集中识字为主、多种方法并举的教法; 重视个体差异, 坚持因材施教。 朱奇涵的《游戏心理学在对外汉语教学中的应用》（2011年）主张通过游戏的方式训练学 习者的听说读写的能力, 如声调韵律训练、字形图画训练、文化交际训练、学游体验训练 等等。

不可否认对于汉字教学研究已经取得了丰富的研究成果, 可是到目前为止还没有一种汉 字教学法是普遍适用的, 这些研究大都立足于汉字本体或汉语作为第二语言的学习者, 却 没有有效地将二者联合起来。在对外汉语教学之汉字教学时, 根据不同教学目的、不同教 学对象, 采取行之有效的教学方法, 不断总结自己的经验、兼采众长、摒弃其短已经成为 大家的共识。基于此, 本文以峇淡慈容学校初中部为研究对象, 研究其汉字教学。

\section{2. 研究问题}

教师能否做好启蒙的工作, 对于学生以后深入学习汉语有深远影响, 因此本文将调查教师 的汉字教学的情况并进行分析。在此的同时经过观察找出一些学习者在学习汉字的过程中 出现的问题, 以下是本文的研究问题:

（一）慈容初中的汉语教师在汉语课堂上常用哪些汉字教学法?

（二）慈容初中生学习汉字的难题及其原因是什么?

（三）教师有效的教学方法? 


\section{3. 研究目的与意义}

本文的研究目的是希望能了解印尼峇淡慈容初中汉语教师所使用的汉字教学方法以及慈 容初中学生在学习汉字的过程中所遇到的问题, 之后, 对于所遇到的问题提供有效的解决 方法。本文的研究结果, 对减少汉字学习难度的解决方法有着非常重要的意义, 此外可以 丰富教师的汉字教学法, 还有, 印尼有关汉字教学的资料比较少, 尤其是以峇淡市为例的 研究非常少见的, 于是本研究的调查结果对印尼峇淡慈容学校初中部的汉语教师或相关研 究者或多或少能提供有一定的参考价值。

\section{二、理论依据和研究方法}

\section{1. 理论依据}

\section{（一）第二语言教学的理论}

吕必松, 2006在《汉语和汉语作为第二语言教学》认为“第二语言教学”是对外汉语教学 的内涵, 是指对于在目的语的环境中学习和使用的第一语言以外的学习者的语言教学。吕 必松也是认为 “第二语言教学” 是根据学习和习得的特点说明的教学性质。从吕必松指出 的第二语言教学来看, 第二语言教学可以理解为其第二语言教学的主要对象是已经掌握了 至少一种语言的学习者, 比如汉语作为第二语言教学是针对母语或第一语言不是汉语的学 习者的教学方法。

Stephen D. Krashen, 1982 认为第二语言教学是学生与教师作为第二语言教育者的互 动过程。E11is, 1992认为第二语言教学的最佳效果在于用它来传输信息之时, 而不是把它 当作学习的目标而精细地讲解之时。它把对于习得的关注, 由老师的“教”转移到学生的“学” 上。从这个两个专家对第二语言教学的观点有着共同点就是第二语言教学是过程, 是教师 与学生传授信息的过程。

\section{（二）第二语言习得的理论}

Jack C. Richards，2005在《朗文语言教学及应用语言学词典》(2005年版) 提到过关 于“第二语言习得”的定义: 广义上来说, 第二语言习得是一个人学了母语之后所学的任何语 言。Larsen-Freeman, D., \& Long, 1991在他们介绍第二语言习得研究的书中, “第二语 言习得” 是任何在母语以外的一种或多种语言。由此可见, 国外第二语言研究者关于 “第二 语言” 的概念是指母语这个 “第一” 语言 之后的、顺序上的 “第二种” 语言, 也可以指任 
何第三、第四种语言, 它既包括在目的语国家学习目的语, 也指在外语环境下学习外语。 从以上的观点我们可以理解为第二语言习得指的是除了母语以外所学的任何语言, 它包括 在目的语国家学习的目的语，也外语环境下学习的外语都是可以被称为“第二语言习得”。

Michae1 Long, 2007认为第二语言习得是一个宽泛的、不断扩展的和内容丰富的领 域。它至少包含了以下的领域, 如: 对第二语言 (包括第三或第四语言) 的即时的与连续地 学习与丧失的研究，也包括对方言、成人与儿童语言的研究, 其中包括学习者的不同动机、 能力和目的。它也包括个体与不同群体接触语言的各种条件, 如正式的与非正式的、混合的 以及外语的、第二语言的通用语言的各种环境。从Long指出的第二语言习得来看，第二语 言习得可以来理解为第二语言习得不只是包含着除了母语之外所学的语言, 它也包括学习 者的对语言不同的动机、能力与目的, 也包括个体与不同群体接触语言的各种条件、也包 括混合语言和外语的。

\section{2. 研究方法}

\section{（一） 文献研究法}

本文通过查阅大量的相关文献，对外汉字教学等相关资料，同时通过万方数据库、中国 知网等各种途径收集一手资料，为论文的撰写提供扎实的准备资料与参考。

\section{（二） 实地考察法}

为了解印尼峇淡慈容学校初中部汉字教学的教学状况，自2019年4月至2020年2月考察 了教学的教学状况和学生的学习状况等。

\section{（三） 问卷调查法}

本文通过调查问卷了解印尼峇淡慈容初中学校的汉语教师的基本情况与学生的基本情况、 对汉字学习的难点及学习方法, 为后面的解决方案提供参考, 从而找出适合印尼峇淡慈容 初中生学习汉字的教学模式, 一共发放了100份问卷, 收集了96份问卷。

\section{（四）访谈调查法}

本文通过访谈法来了解教师们在汉字教学方面的相关问题和教师们进行汉字教学所使用 的教学方法, 整理访谈结果, 分析慈容初中的汉语教师对汉字教学中所存在的问题。本文 主要访问慈容学校初中部校长、汉语教师和学生。

\section{（五） 统计分析法}

本文将对已收集的教师和学生的问卷调查结果通过画正字的统计分析法方法进行分析， 算出每种选项的百分比并将结果反映到论文中。 


\section{（六） 描述法}

本文通过统计得出的结果进行分析, 然后再把已分析好的慈容初中的汉语教师情况、 学生基本情况、汉语课程设置情况、学生汉字学习的情况与教师使用汉字教学法描述出来, 并且将研究过程中所发现的问题进行分析解决问题, 最后归纳、总结汉字教学的策略和方 法。

\section{三、印尼峇淡慈容初中学生学习汉字的难点}

\section{1. 学生对汉字学习的看法}

汉字是属于汉藏语系，也是表意文字，而印尼语是属于印欧语系的表音文字。对于印尼 学生来讲, 汉字是属于另一种语言的文字。汉字到底难还是不难, 通过问卷调查本文得出 的了一下结果:

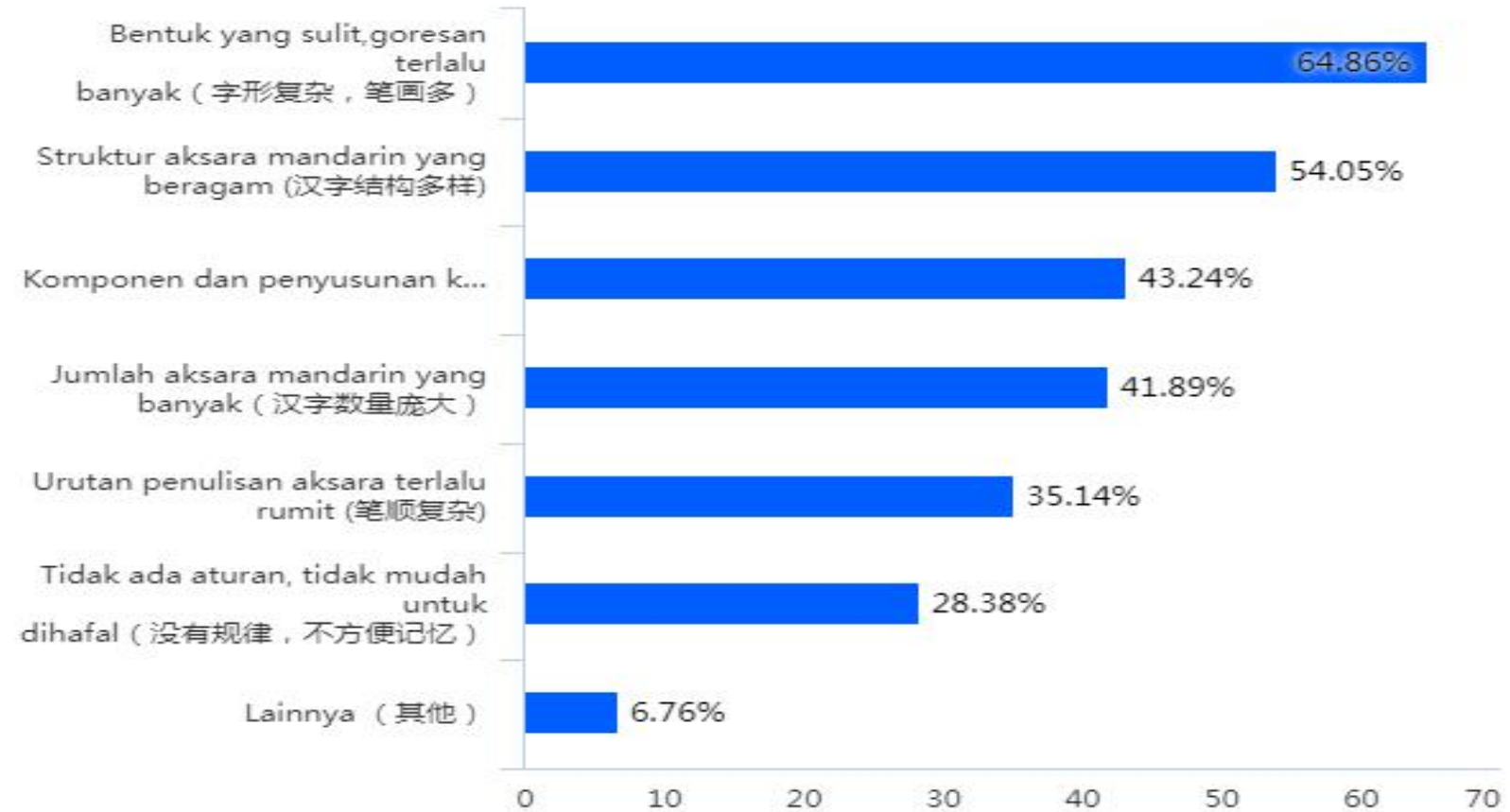

图1. 学生汉字学习的难点

从上述图1可看, 对于印尼峇淡慈容初中生来看, 有 $68.86 \%$ 学生认为汉字字形比较复杂, 笔画比较多, 使汉字比较难学; 有54.05\%学生认为汉字结构多样, 使学习时难于掌握; 有 43. $24 \%$ 学生认为汉字的部件和部件组合方式多样, 很难巩固; 有 $41.89 \%$ 学生认为汉字的数 量庞大, 很难背; 有 35.14 学生认为汉字的笔顺复杂, 难于学好; 28. 38\%学生认为, 汉字没 有规律，不方便记下; 有 $6.76 \%$ 学生选择其他, 比如汉字认读和汉字书写方面比较难等。 
从上述结果可看, $50 \%$ 以上的同学认为汉字的字形、笔画、结构是比较难掌握的, 这一 些影响了学生的学习态度, 同时也影响了学生写汉字的掌握性程度。

\section{2. 慈容初中生汉字书写偏误分析}

本文向印尼峇淡慈容初中学校的汉语教师收集了一些学生在作业, 听写, 练习本中出现 的汉字偏误资料主要是从七年级和八年级学生的初级班和中级班作业和练习本为研究资料。 根据资料分析, 得知学生们在汉字书写偏误最大的问题表先在于笔画偏误、笔顺偏误和结 构偏误等。以下是其资料和信息:

\subsection{1. 笔画偏误}

笔画是构成汉字最基本的元素。王汉卫, 苏印霞在《论对外汉语教学的笔画》（2014年） 认为笔画教学是汉字教学的关键, 笔画比字母更需要教学。而笔画问题也更能反映出一个 汉语学习者的书写水平。经过本文对所搜集的资料进行划分, 印尼峇淡慈容初中生在汉字 笔画方面的问题主要有以下三种: 笔画变形、笔画增减, 以及笔画组合错误。

\section{（一）笔画变形}

笔画形态的偏误, 指的是在汉字书写过程中笔画形态出现了变形、断笔、连笔等偏误现 象。例如:

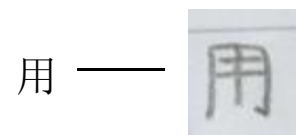

快
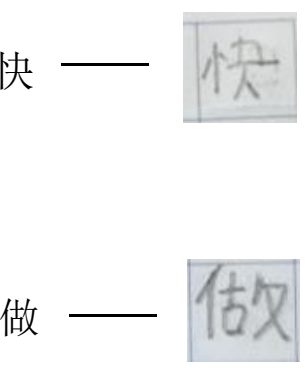

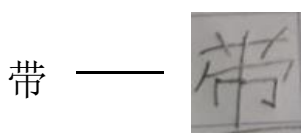

卷

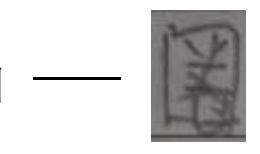

狸 一 $\searrow$ 里
是

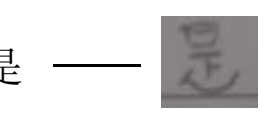

\section{（二）笔画增减}

（1）增加笔画

笔画增加的偏误, 指的是在汉字书写过程中增加了多余笔画的偏误现象。例如:

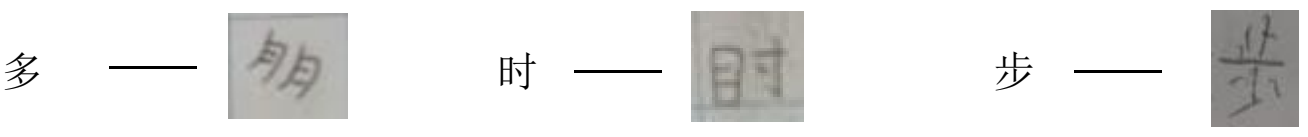


得

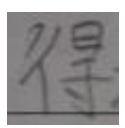

百

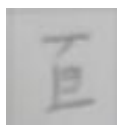

(2) 减少笔画

笔画减少的偏误，指的是在汉字书写过程中笔画丢失的偏误现象。例如:

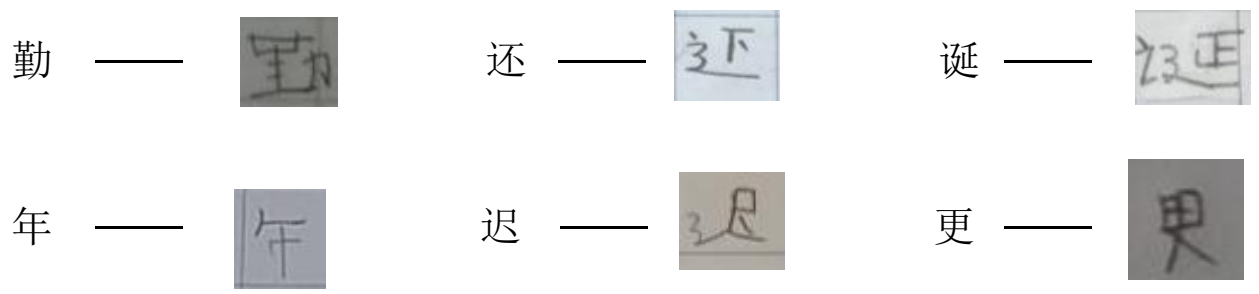

\section{（三）笔画组合错误}

笔画组合的错误或偏误，指的是在汉字书写过程中笔画的组合方式，即相离、相接、 相交出现了组合关系不当或者位置不当的偏误现象。例如:

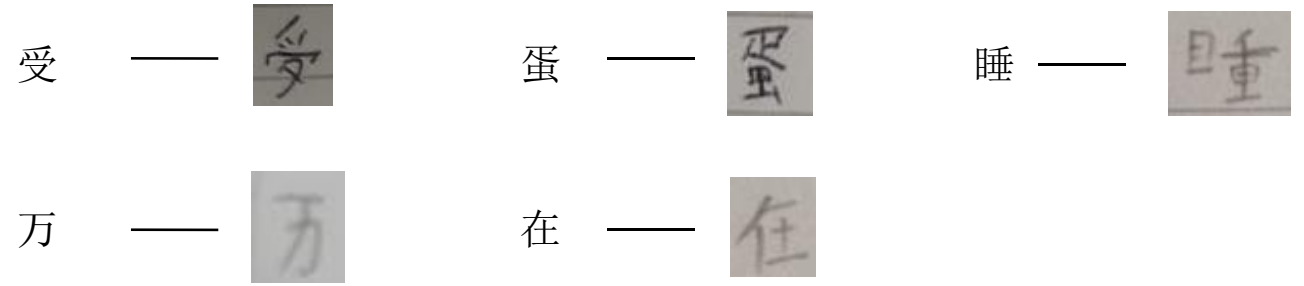

\section{2. 2. 笔顺偏误}

每个汉字的笔画组合都是有顺序的。在书写汉字时，笔画的先后顺序就是笔顺。由此可 见, 笔顺在书写汉字这一方面至关重要。根据分析, 本文发现印尼峇淡慈容初中生在汉字 笔顺的书写出现了以下几类偏误现象:

\section{（一）笔顺组合偏误}

笔顺组合偏误是指书写汉字时对笔画进行错误的组合, 造成笔画增加或减少的偏误。印 $\#=-=\mp A \#$ 互田

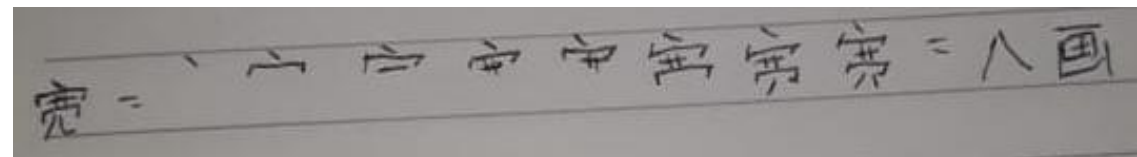


以上例句可以看出, 慈容初中生把“丑”字的第一笔“横折”分拆为“横+横”造成笔画增加 的偏误。“宽”字中“广” 的写法应该是“点+点+横钩”, 共三笔的, 但学生却把它组合为“点+ 敉横钩”造成笔画减少的偏误。

\section{（二）笔顺规则偏误}

笔顺规则偏误指的是书写汉字时，汉字笔顺违背了笔顺规则的偏误。例如:
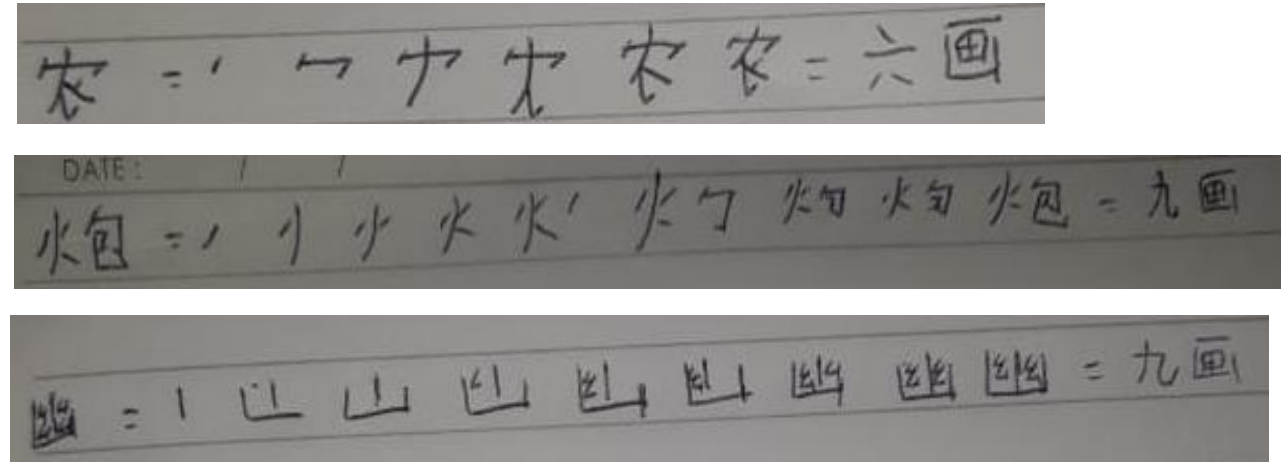

以上例句显示，慈容初中生把“农”字的笔顺序“点+横撇/横钩+渽+坚提+潄+捺” 写成“点

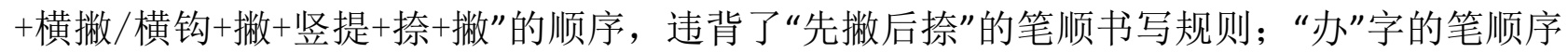
“横折钩+潄+点+点”写成“撇+横折钩+点+点”, 违背了“先中间后两边”; “炮”字里“火”也违背 了“先两边后中间”的规则; “幽”的笔顺序也违背了“先里后外”的规则。

\section{2. 3. 结构偏误}

刘靖年, 2011在《汉字结构研究》提到所谓汉字结构, 有狭义和广义两种含义: 狭义的 汉字结构, 仅指汉字结构成分的组合方式; 广义的汉字结构, 还包括汉字各层次结构成分 本身，如整字、偏旁、部件、笔画（线条）等形体要素。根据本文对所搜集的资料进行划 分, 印尼峇淡慈容初中生在汉字结构方面的主要问题是在于比例失调和空间位置不当的错 误。

\section{（一） 比例失调}

比列失调指的是偏旁过大，主题过小，或者上下比例不协调。

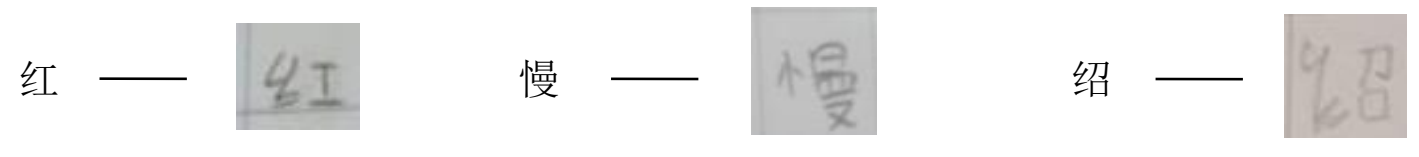




\section{（二） 空间位置不当}

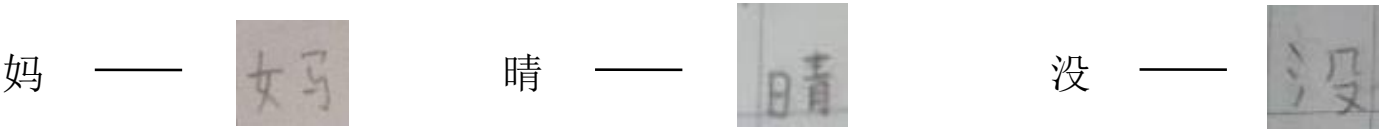

结构比例不当也会造成结构偏误。从上面的例子我们可以看印尼慈容初中生经常犯的错 误。比如: “妈”、“没”、“晴”字的汉字部件与部件之间的距离太远产生了结构偏误。比如: “晴”字的“日”“字过于往下写。这些字都给人一种空间安排不合理的感觉, 不符合汉字的审 美标准。

\section{3. 印尼慈容初中生汉字习得偏误原因分析}

\section{（一）学生学习汉语的基本信息}

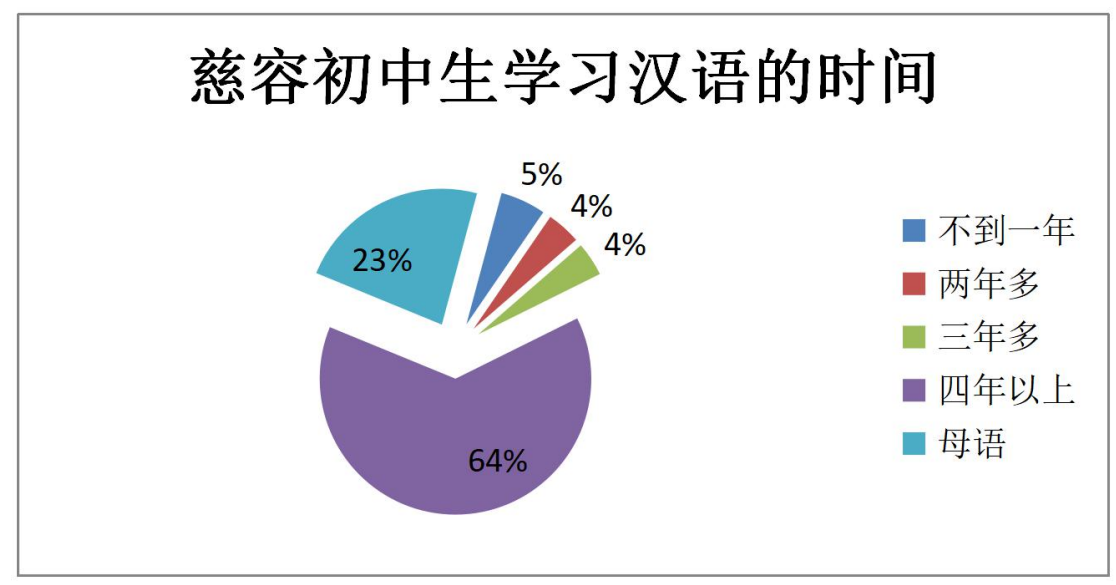

图2. 学生学习汉语的时间

调查中发现, 有 $64 \%$ 学生都已经 4 年以上学习汉语的, 有 $23 \%$ 学生从小已经接触汉语。而 有 $4 \%$ 的学生 3 年多学习汉语, 有 $4 \%$ 的学生 2 年多学习汉语, 只有 $5 \%$ 学生学习汉语时间不到 1 年。 从上述可得知印尼峇淡慈容初中学生的汉语水平有一定的基础, 因为学习汉语的时间足够 长，而且有些学生已经从小接触汉语，而只有小部分的学生刚开始学汉语的。

\section{（二）学生汉字学习态度情况}

根据一年级和二年级（初级班和中级班）学生调查问卷统计了学生汉语学习与汉字学习 态度情况，统计结果如以下： 


\section{慈容初中生汉字学习态度情况}

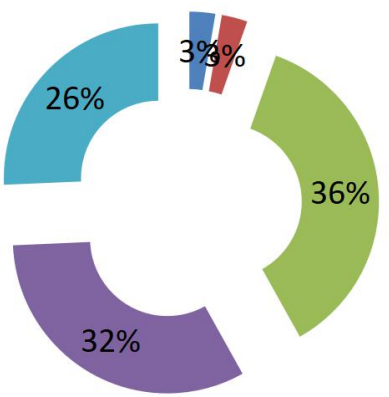

口非常不喜欢

不喜欢

- 一般

喜欢

非常喜欢

图3. 初级班与中级班学生汉字习态度情况

本文通过对印尼峇淡慈容初中学生的调查结果发现, 有36\%的印尼峇淡慈容初中初级班 与中级班的学生对汉字学习的态度表示一般, 有 $32 \%$ 的初中生对汉字学习的态度表示喜欢, 有 $26 \%$ 的初中生对汉字学习的态度表示非常喜欢, 而只有3\%的初中生对汉字学习的态度表示 不喜欢还有3\%的初中生对汉字学习的态度表示非常不喜欢。从上述可看, 学生对汉语课程 没有绝对的态度。

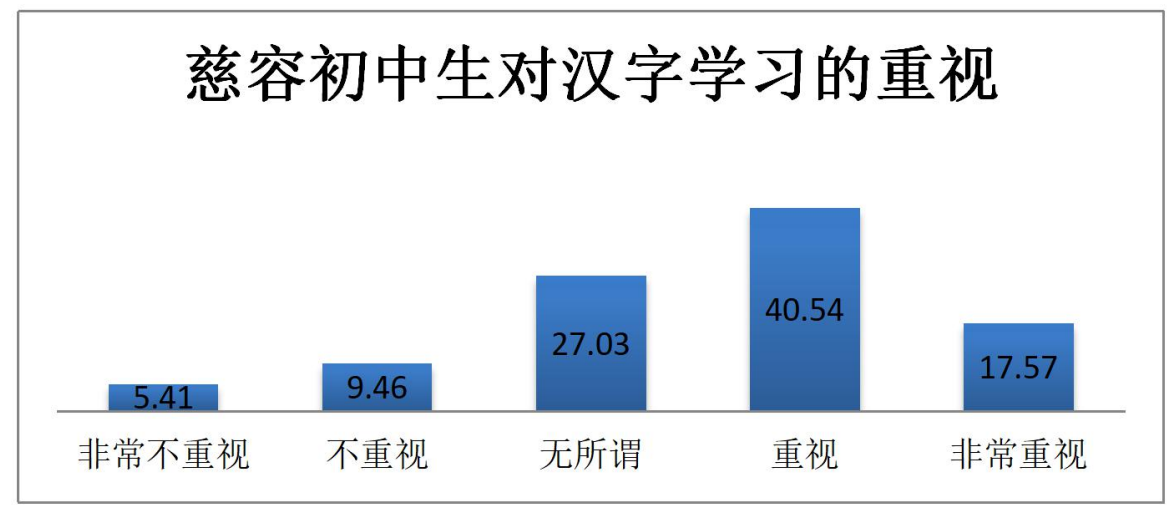

图4. 初级班与中级班学生对汉字学习的重视度

如以上的图可得知, 有 $40.59 \%$ 的印尼巴淡慈容初中生的初级班与中级班认为学会汉字 书写重要, 有 $17.57 \%$ 的学生认为学会汉字书写非常重要, 有 $27.03 \%$ 的学生的态度表示无所 谓, 有 $9.46 \%$ 的学生认为汉字学习不重要, 有 $5.415 \%$ 的学生认为学会汉字书写非常不重要。 从上述结果可看，多数的同学还是认为汉字教学是比较重要的部分。 


\section{（三）学生汉字学习的情况}

（1）注意汉字笔画程度

为了了解印尼峇淡慈容初中学生学习汉字的情况, 本文通过问卷调查请印尼峇淡慈容 初中生选出出自己经常使用的学习方法。以下是其资料信息:

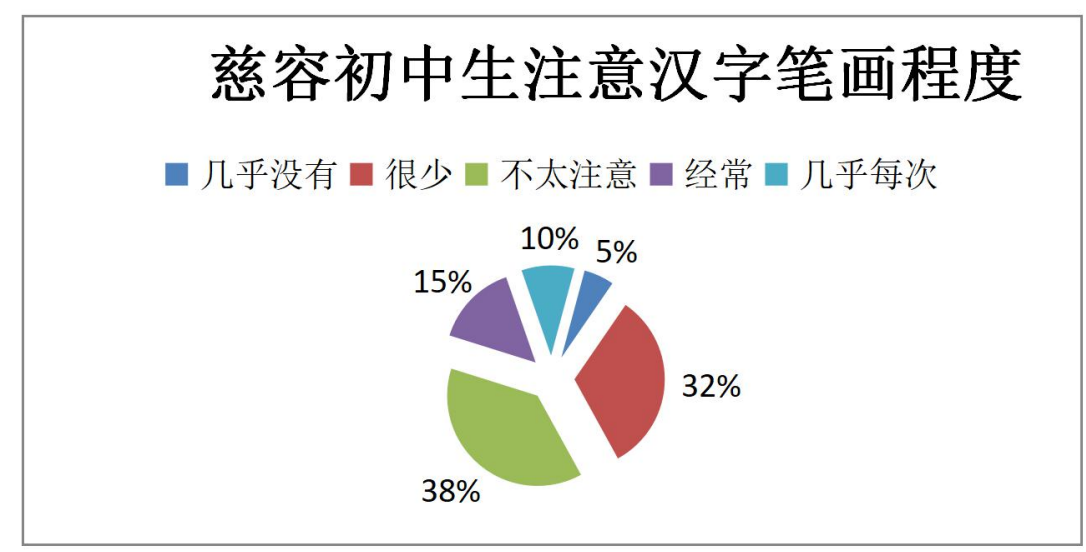

图5. 学生汉字笔画的学习方法

据统计可知, 有38\% 的学生学习汉字的时候不太注意汉字的笔画, 有32\%的学生学习汉 字的时候很少注意到汉字的笔画, 有5\%的学生学习汉字的时候很几乎没有注意到汉字笔画, 而只有 $15 \%$ 的学生学习汉字的时候经常注意到汉字笔画, 此外, 还有 $10 \%$ 的学生学习汉字的 时候几乎每次会注意到汉字的笔画。

从上面的数据我们可以了解大部分学生对汉字笔画的注意程度比较低, 在汉字的书写 方面经常忽略了汉字笔画正确的写法。因此汉字笔画成为他们汉字学习的难点。

（2）注意汉字偏旁程度

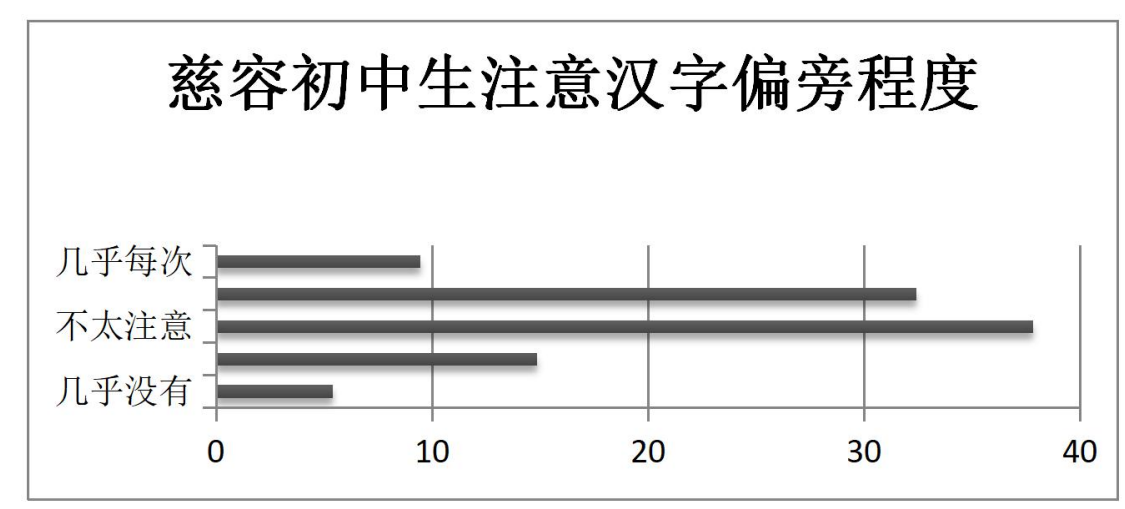

图6. 学生汉字偏旁部首的学习方法

据调查结果显示, 有 $33.78 \%$ 的学生学习汉字的时候不太注意汉字的偏旁部首, 有 $31.08 \%$ 的学生学习汉字的时候很少注意到汉字的偏旁部首, 有 $5.41 \%$ 的学生学习汉字的时候 
很几乎没有注意到汉字偏旁部首, 而只有 $25.68 \%$ 的学生学习汉字的时候经常注意到汉字偏 旁部首, 此外, 还有 $4.05 \%$ 的学生学习汉字的时候几乎每次会注意到汉字的偏旁部首。

从以上的数据, 我们可以了解大部分学生对汉字偏旁的注意程度很低, 在汉字的书写 方面经常忽略了汉字认知单位的部件。因此汉字部件成为他们汉字学习的难点。

（3）注意汉字笔顺程度

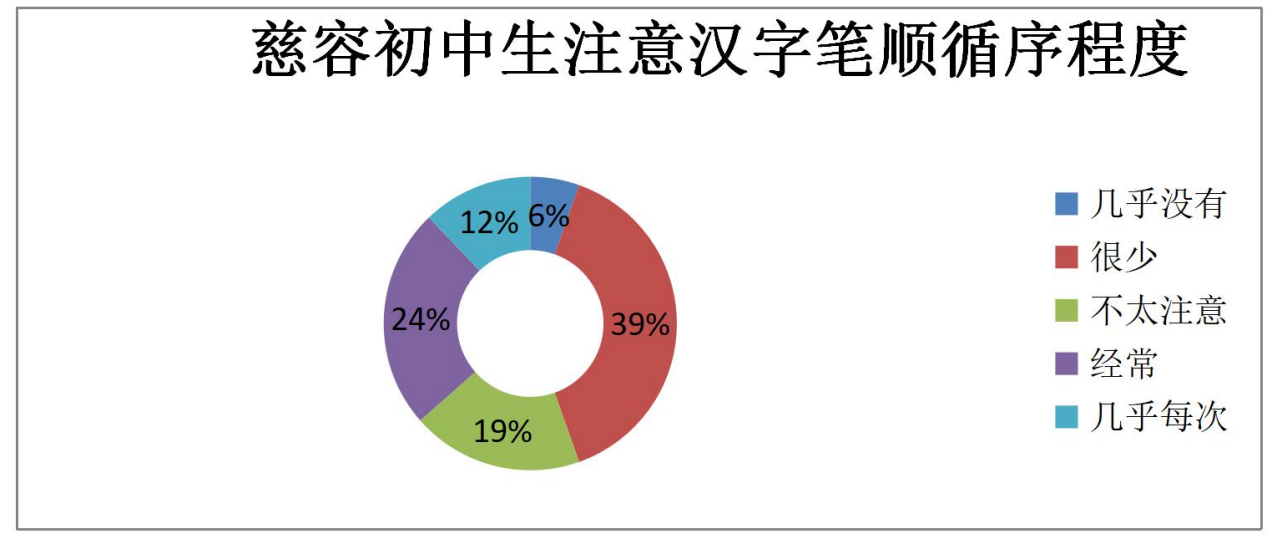

图7. 学生汉字笔顺学习方法

据上图所示, 有 $39.19 \%$ 的学生学习汉字的时候很少注意到汉字的笔顺, 有 $18.92 \%$ 的学 生学习汉字的时候不太注意到汉字的笔顺, 有 $5.41 \%$ 的学生学习汉字的时候很几乎没有注意 到汉字笔顺, 但也有 $24.32 \%$ 的学生学习汉字的时候经常注意到汉字笔顺, 此外, 还有 12. 16\%的学生学习汉字的时候几乎每次会注意到汉字的笔顺。

从上面的数据我们可以了解大部分学生对汉字笔顺循序的注意程度很低, 学生们在汉 字的书写方面经常忽略了汉字笔顺正确的循序。因此汉字笔顺成为他们汉字学习的难点。

\section{（四）学生汉字自习的情况}

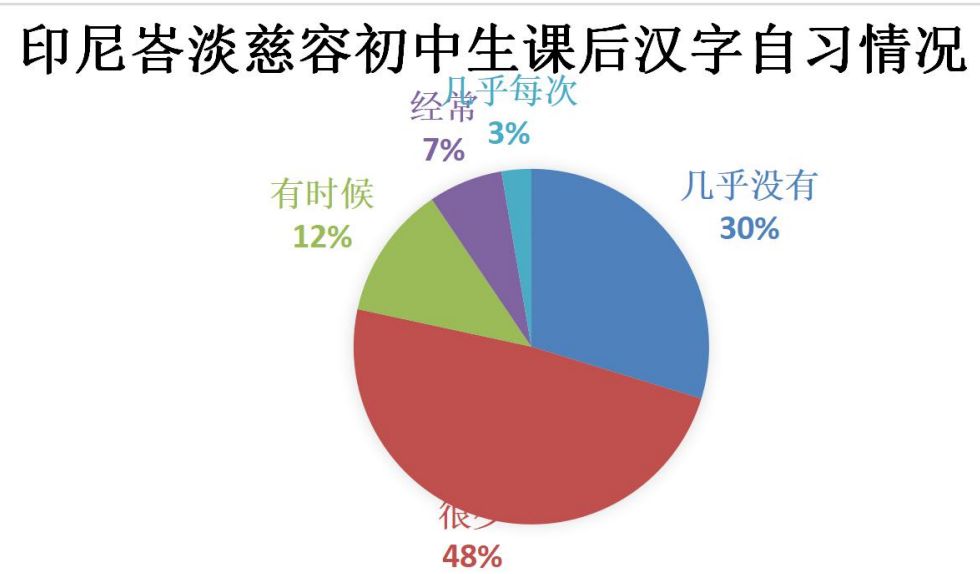

图8. 学生汉字自习情况 
从以上的数据我们可得知, 印尼慈容初中生对汉字学习的自我提高的能力比较低。有 48\% 的学生很少在课后主动复习或自习汉字, 有30\%学生几乎没有在课后主动复习或自习汉 字, 有 $12 \%$ 的学生有时候在课后主动复习或自习汉字, 而只有 $7 \%$ 的学生经常在课后主动复习 或自习汉字, 此外, 还有3\%的学生几乎每次在课后主动复习或自习汉字。

按照以上的信息我们发现, 印尼峇淡慈容初中生缺乏学习的主动性与积极性, 而且他们 母语是印尼语, 印尼文字与汉字是两种截然不同的文字系统, 这影响了他们的学习态度。

\section{四、对印尼峇淡慈容初中生汉字教学对策}

\section{1. 教师汉字教学建议与对策}

根据调查结果的基础上与理论上, 本文试着提出对印尼慈容学校初中部的汉教学的若干 建议。

\section{1. 1. 针对印尼慈容初中汉语教师自身的教学建议}

通过对印尼慈容初中汉语教师的相关调查与分析发现教师在进行汉语教学的过程当中还 存在着一些不足的地方。本文针对印尼峇淡慈容初中的汉语教师自身提出一些建议:

（一）印尼慈容初中的汉语教师应当重视汉字教学。

目前在印尼慈容初中的汉语教学中还未有专门的汉字课, 但这不代表教师在上课中就无 需对汉字进行专门的教学。为什么教师不大重视汉字教学? 有可能因为教师的年龄比较轻, 自身缺乏汉字教学的经验, 在汉字理解和教学方面存在着众多的不足; 此外, 教师未全面 地掌握汉字的各种部首、结构、写法规律等, 这样影响了教师对汉字教学的积极性; 还有, 备课不足, 教师教学前应当做好充分准备, 这样可以适当地在课堂上进行汉字讲解等。有 一句好话, 即只有教师自身重视汉字的教学才能引起学生对汉字的重视。

（二）多参加专业性的汉字教学的相关培训。

中国有一句老话, 即“活到老, 学到老”, 还有“学无止境”, 也就是说, 教师应当不断的 提升自己, 参加汉语教师培训是一种解决问题的方法之一, 通过参加教师培训, 教师可以 提高自己的汉语教学的教学能力, 特别是汉字教学能力。 


\section{1. 2 针对印尼慈容初中汉语教师汉字教学法的建议}

\section{（一）使用趣味性的教学方法进行汉字教学}

蔡丽在《华文趣味教学理论与实践》（2015年）提到“作为华文教师应注重通过华文课 堂教学的趣味性来提高学生学习华文的兴趣”。所以本文是以趣味性的教学方法为印尼慈容 初中学校提出建议, 因为如果学生对学习汉字有了浓厚的兴趣, 他们就会主动, 积极地探 索并运用汉字, 这样就能使其书写能力得到良好的发展。

本文通过教师访谈调查得知, 游戏法也是慈容初中生最喜欢的课堂教学形式之一。通过 游戏法可以让有兴趣的学习汉字, 增加喜悦的学习气氛, 特别是针对初级阶段的学生。由 于学生目前只能从课堂上习得汉字, 所以在汉字教学中教师应该多运用一些灵活、新鲜的 汉字教学手段让学生们喜欢上汉字, 抛开对汉字难学的思想。运用一些小游戏对汉字的结 构、部件进行汉字教学, 提升他们的兴趣, 同时端正他们对汉字的想法。以下是本文提出 汉字游戏法的例子:

\section{（1）汉字笔画游戏}

第一, 《看谁写的汉字多》的游戏活动。这次活动的目标是为了能够培养学生的联想 及组字能力还有帮助学生复习刚学过的笔顺也能够更加巩固对汉字笔画的理解。

活动准备: 老师先准备学生学过的汉字。

活动过程：（a）老师将全班学生分成5个大组每组5-6个人（看情况）; （b ）老师可 以使用PPT展示汉字也加上相关的问题, 比如: “画”字是以什么笔画组成的? ; (c) 学生看 完之后, 各组的成员要接着在板书写出笔画并且说出笔画的名称, 答对就加分; (d) 最后 看哪个组得分高, 用奖品或表演节目的形式适当予以奖惩。

\section{（2）汉字笔顺游戏}

第二, 《笔顺接龙》的游戏活动。通过这个游戏教师能够培养学生的快速思考及反应 能力和帮助学生复习学过的汉字的笔顺, 巩固学生对汉字笔顺的理解。

活动准备：老师将全班学生分成5个大组每组 $5-6$ 个人。

活动过程：（a）老师请全班学生做好准备; （b）老师将每组汉字分成几列分别板书 在黑板上或者学生可以使用一张纸来写; (c) 请一些学生上来。每组第一个学生写每个字 的第一笔, 第二个学生再写每个字的第二笔, 第三个学生写每个字的第三笔, 依此继续进 行, 直到写完所有笔画; (d) 各组写完后, 着哪一组写笔顺的错误少, 再看哪一组的同学 用的时同少。最后评比出每组的名次。 


\section{（3）汉字偏旁部首游戏}

第三, 《谁猜的多》的游戏活动。这次活动的目标是为了能够培养学生的联想及组字 能力还有帮助学生复习学过的汉字及偏旁, 部件, 更加巩固对汉字偏旁, 部件的理解。

活动准备: 老师先准备一些跟偏旁部首有关的图片, 老师可以使用PPT来展示图片。

活动过程：（a）老师将全班学生分成5个大组每组5-6个人; (b) 老师请全班学生做 好准备; （c）老师将把部首的图片展示给学生们看 (d) 每个队员轮流说出部首的名称;

（e）最后看哪个组得分高，用奖品或表演节目的形式适当予以奖惩。

\section{（二）学生自己查找出错原因, 有针对性纠正错别字}

教师要努力营造和谐的教学气氛, 充分调动学生的积极性和主动性, 鼓励学生自己找 出出现错别字的原因, 教师根据出现错别字的原因有针对性进行纠正。例如当学生出现错 字的时候, 就要从分析字形入手, 在教学过程中我们发现学生书写汉字出现错误。针对学 生写错字的现象, 我们应该注重从分析字形入手纠正错别字。如果学生出现的是别字, 我 们就要从字义上纠正错别字。这就要求在教学中通过具体语境、词境限制其意义的方式来 纠正错别字。例如有些学生常把“已”和“已”混淆起来, 我们帮助学生在区别这两个字的时候 可以通过联词的方法。把“已”组成“已经”等, 把“已”组成“自己”。通过分析这些词义可以使 学生一目了然地正确辨析别字。

\section{（三）创办丰富多彩的活动，纠正错别字}

（1）通过小组之间的合作，纠正错别字。

做法一: 把全班学生按一人分成合作小组, 以小组为单位开展消灭错别字的活动。在分 组的时候要注意层次性, 以程度好的学生带动程度差的学生, 在互相分享方法的情况下共 同进步;

做法二：以同桌为小组, 让同桌之间相互纠正错别字。在学习生字之后, 同桌之间相互 听写所学生字以达到巩固生字的效果, 在相互听写生字的过程中发现错别字共同纠正。为 了让更多学生参与到活动中, 教师可以采用小组竞赛和奖励的方式来调动学生的积极性。 对于成绩突出, 进步的小组和个人可以采用发奖状和发文具的方式进行鼓励。

（2）创办错别字自助板报

以纠正错别字为主体, 鼓励学生把自己在识字过程中的纠正过的错别字写在板报上, 并 
写出出错原因, 再写出纠正的方法, 进而以正误对比的形式与大家分享纠正错别字的经验。

\section{（四）使用字帖布置汉字书写练习和听写, 及时集中讲解学生书写错误并让学生订正}

每次课结束后, 都要布置生词抄写作业, 即抄写生词五遍和下次课的听写任务。布置生 词抄写, 可以巩固所学生词, 强化笔画、笔顺的书写练习, 五遍抄写后学生基本能够记忆 汉字。听写任务能够提醒学生复习已学知识, 提高汉语学习的连续性。但是给抄写的任务 时, 教师可以使用字帖要学生能够模仿端正的汉字。减少学生写字是出现字不端正的现象。 作业和听写都需要及时批改和集中讲解。集中讲解起到了强化和警示作用, 让学生强化自 己正确的汉字知识, 了解到自己所犯的偏误, 也可以了解别人所犯的偏误, 避免再犯相同 的错误。

\section{2. 学生学习汉字建议与对策}

\section{2. 1. 学生要学会制定学习计划}

从学生相关的调查结果发现印尼慈容初中生并不擅长甚至排斥为自己的学习制定一份 计划。而在这个方面, 教师可担当主导作用, 用自己的方式鼓励学生制定一份汉字学习计 划, 分时间段的记录自己的汉字学习情况, 最后再由教师对学生的汉字学习进展有针对性 的评比。这样不仅让学生在学习中看到自己的进步同时也能从中发现自己的学习问题, 并 在教师的帮助下及时调整自己的学习策略。

\section{2. 2. 使用提高记忆力的学习方式}

表1。印尼峇淡慈容初中学生识记汉字方法

\begin{tabular}{ccc}
\hline 慈容初中学生识记汉字方法 & 人数 & 比例 \\
\hline 用拼音记字义 & 48 & $64.86 \%$ \\
通过上下文语境记字义 & 27 & $36.49 \%$ \\
用形声字的形旁 & 19 & $25.68 \%$ \\
其他 & 15 & $20.27 \%$ \\
\hline
\end{tabular}

黄彦（2012）认为识记汉字指的是辨别出具体汉字的特点并加以联系, 更加有效地识 别和记忆汉字。本文针对慈容初中生识记汉字方法的特点提出适合学生们的解决方案。从 以上的数据统计可得知, 有 $64.86 \%$ 的印尼峇淡慈容初中生识记写汉字的方法是使用拼音来 
记字义, 有36. 49\%的印尼峇淡慈容初中生识记写汉字的方法是通过上下文语境记字义, 有 $25.68 \%$ 的初中生识记写汉字的方法是用形声字的形旁来记汉字，而有 $20.27 \%$ 的初中生学习 选上了其他的学习方法就是使用抄写的方法来记汉字。

朱纯（1994）在认知心理学的理论提到过 “语言既是认识发展的产物又是认识世界的 工具。语言学习是这样一种认知活动: 学习者依靠原有的认知结构, 激活人脑中的想象图 景、概念系统, 经过思想联想等获取信息、认识事物。” 1 。根据以上的调查结果以及朱纯 的观点我们可得知, 学习者在学习汉字的过程当中也靠记忆力来学习汉字, 所以本文以提 高记忆力的学习方式提出印尼慈容初中生学习汉字的建议与对策。

\section{（一） 形象记忆法}

要快速的记住汉字, 我们可以靠形象思维来学习汉字, 通过具体形象来帮助记忆刚学过 的汉字。比如: “休”字就以“人依靠木”变成“休”字; “林”字就以“双木”变成林。这个做法不 只是能帮助哦我们快速的记住汉字而且还能提高学生学习的兴趣。

\section{（二） 部件记忆法}

以单独的汉字来记比较复杂的汉字。比如：“和”字是以“禾”与“口”组成的字; “明”是以 “日”与“月”组成的字; “翻”字是以“番”和“羽”组成的字。

\section{（三）利用部首学字}

使用汉字的偏旁部首来记汉字。以汉字偏旁部首了解汉字的字义。如: “注”是跟水有 关的字; “口”是跟口有关的字; “井”是跟植物有关的汉字。

\section{2. 3. 打好笔顺书写规则的基础, 掌握汉字的笔画及结构}

据调查结果显示，印尼峇淡慈容初中学生虽然在汉语教学过程中已经接触过汉字笔顺的 基本书写规则, 但掌握得不深入。所以, 在汉语学习的过程中, 学生首先要通过汉字笔顺 的书写练习，巩固汉字书写的基本规则。在书写过程中遇到问题时，要及时向老师提问， 不能随意类推已掌握的书写规则。对于笔画和结构, 学生要通过多次的书写练习, 有意识 地对比不同汉字相似的笔画, 掌握每个汉字的笔画。在此基础上, 培养自己的汉字学习能 力, 自己把同一个偏旁的汉字集中起来记忆, 养成推测汉字意思的能力。也把自己写的汉 字能够端正，更有美观。

${ }^{1}$ 朱纯. 外语教学心理学 [M] 上海: 上海外教出版社, 1994: 123-134 


\section{五、结语}

本研究针对印尼峇淡慈容初中汉语教师的汉字教学与慈容初中生的汉字书写偏误进行调 查与分析。本文使用文献研究法、实地考察法、问卷调查法、访谈调查法、统计分析法、 以及描述法的步骤进行, 通过问卷调查收集, 对96份收回的有效问卷进行分析, 在结合理 论的基础上对学生的汉字书写偏误进行分类, 找出偏误产生的原因, 还有通过访谈法, 对 4 位汉语教师进行访谈得知他们所使用的教案学方法, 找出教学方法的优势及不足的地方, 最后提出较有针对性的汉字教学的建议与对策。

通过调查, 慈容初中学生在笔画偏误与结构偏误率高。慈容初中生由于对汉字感到不新 鲜, 在书写过程中便产生一种“随意性”, 而且在汉字学习的过程当中缺乏了学习的主动性与 积极性, 造成了他们在笔画与结构方面产生偏误。在笔顺偏误这一方面, 笔顺规则的偏误 率最高。慈容初中生经常因为对汉字笔顺书写的基本规则掌握不牢，而类推本该用笔顺补 充规则书写的汉字的书写方式，造成笔顺偏误。

根据以上结论可以看出, 他们产生偏误的主要原因是因为汉字很复杂, 学生也缺乏了学 习的主动性与积极性, 在加上汉语作为学生的第二语言习得。因此本文提出了针对印尼慈容 初中汉语教师自身的教学建议和在汉字教学中运用游戏以提高课堂的趣味性, 从而减少慈容初 中生汉字学习的畏难情绪。另外, 本文也提出制定学习计划以及以培养记忆力的汉字学习 方法, 以帮助学生克服语言学习中汉字学习这一难点, 提高汉字学习的效率。 


\section{Jurnal Cakrawala Mandarin

\section{参考文献}

[1] Ellis, R.(1992).Second Language Acquisition and Language Pedagogy.

[2] Jack C. Richards.(2005). 朗文语言教学及应用语言学词典. 35(2), 163-168.

[3] Larsen-Freeman, D., \& Long, M. H.(1991).An Introduction to Second Language Acquisition Research.

[4] Michael Long.(2007).Second Language Acquisition and Task-Based Language Teaching. 124125.

[5] Stephen D. Krashen.(1982). Second Language Acquisition and Second Language Learning. 2, 55-59.

[6] 蔡丽. 《华文趣味教学法理论与实践》, 暨南大学出版社, 2015.167-203.

[7] 程棠. 《对外汉语教学学科发展说略》, 汉语学习,2004(06):42-50.

[8] 黄彦. 《民俗汉字研究》, 上海师范大学,2012.

[9] 刘靖年. 《汉字结构研究》, 吉林大学,2011.

[10] 吕必松. 《汉字教学与汉语教学》，语言文字应用,1993(02):27-31.

[11] 吕必松. 《汉语和汉语作为第二语言教学》, 北京大学出版社, 2006.120-134.

[11] 徐贝贝. 《初级阶段对泰汉字笔画笔顺教学法与部件结构教学法教学效果对比分析》, 广西大学,2016.

[13] 唐根基（Herman）。《印尼语中的汉语称说研究》, 《世界华文教育》, 北京语言学院, 2016.6.

[14] 唐根基（Herman）.《印尼苏南省巨港市区华文教育历史发展与现状分析》毕业论文, 暨南大学, 2011.6.

[15] 万业馨. 《文字学视野中的部件教学》，语言教学与研究,2001(01):13-19.

[16] 王丽媛. 《对外汉语教学中的汉字教学研究》, 兰州大学,2012.

[17] 王晓鹏. 《识字教学在初级阶段对外汉语汉字教学中的应用研究》, 重庆师范大学,2017.

[18] 王汉卫,苏印霞. 《论对外汉语教学的笔画》，世界汉语教学,2012,26(02):266-275.

[19] 王爱云. 《当代中国文字改革研究》，武汉大学,2014.

[20] 翁晓汶(LANY DIANA). 《华裔中级水平学生的汉字书写偏误分析与教学对策》, 广东 外语外贸大学, 2015 .

[21] 余国江. 《传统识字教学的优点及其对对外汉字教学的启示》, 教育与职 业,2007(09):120-122. 
[22] 朱奇涵. 《游戏心理学在对外汉语教学中的应用》, 考试周刊, 2011:5-8.

[23] 朱纯. 《外语教学心理学》, 中国校外教育,1994(23):94.

\section{Data Penulis}

\section{Penulis Pertama}

Nama

Negara

Program Studi

Perguruan Tinggi

HP

Email

\section{Penulis Kedua}

Nama

: Dr. Herman

Negara

: Indonesia

Perguruan Tinggi

Program Studi

Email
: Meta Eka Putri（唐葵鸿）

: Indonesia

: Pendidikan Bahasa Mandarin

: Universitas Universal, Batam（世界大学）

: +6282285214508

: metaeka123@gmail.com

: Pendidikan Bahasa Mandarin

: hermanuvers72@gmail.com 